J. Lake Sci.(湖泊科学), 2017, 29(1):9-21

DOI 10. 18307/2017. 0102

(C) 2017 by Journal of Lake Sciences

\title{
基于水质改善目标的太湖适宜换水周期分析
}

\author{
王冼民 ${ }^{1}$, 翟淑华 $^{2}$, 张红举 $^{2}$, 胡维平 ${ }^{3}$, 李钦钦 ${ }^{4}$, 韩 涛 $^{3}$ \\ (1: 广东海洋大学农学院资源与环境系, 湛江 524088 ) \\ (2: 水利部太湖流域管理局水保局, 上海 200434) \\ (3: 中国科学院南京地理与湖泊研究所湖泊与环境国家重点实验室,南京 210008) \\ (4: 中国科学院大学,北京 100049)
}

摘 要: 准确估算换水周期对于研究湖泊水体化学、生物变化以及污染物迁移、扩散、转化有着重要意义,换水周期是湖 泊的一个重要环境参数. 根据 2010 年实测水文、气象和环湖水量、水质条件, 建立 3 组情景模式: 第 1 组为实况方案,第 2 组是环湖水量倍比缩放方案, 第 3 组为望虞河水量倍比缩放方案. 采用 EcoTaihu 模型模拟 3 组情景模式下太湖及各湖区 营养盐状况, 并根据实测结果对模型进行校验. 模型计算结果表明: 在 2010 年太湖水文、气象条件下, 150 160 d 换水周 期条件下太湖氮、磷浓度最低,即太湖适宜换水周期为 $150 \sim 160 \mathrm{~d}$.

关键词: 换水周期;EcoTaihu 模型; 太湖; 营养物质循环; 富营养化

\section{Research on appropriate hydraulic retention time on basis of water quality improvement of Lake Taihu}

\author{
WANG Xianmin ${ }^{1}$, ZHAI Shuhua ${ }^{2}$, ZHANG Hongju ${ }^{2}$, HU Weiping ${ }^{3}$, LI Qinqin ${ }^{4} \&$ HAN Tao $^{3}$ \\ (1: Department of Resources and Environment, School of Agriculture, Guangdong Ocean University, Zhanjiang 524088, P.R. \\ China) \\ (2: Water Resources Conservation Bureau, Taihu Basin Authority, MWR, Shanghai 200434, P.R.China) \\ (3: State Key Laboratory of Lake Science and Environment, Chinese Academy of Sciences, Nanjing 210008, P.R.China) \\ (4: University of Chinese Academy of Sciences, Beijing 100049, P.R.China)
}

Abstract: Hydrolic retention time in an aquatic environment of lake water has long been of interest to biological limnologists because it is very important for determining lacustrine ecosystem health and sensitive to pollution threats. To evaluate the retention time of Lake Taihu, three scenarios are set up according to the measured data of hydrological, meteorological, boundary conditions of water quantity and quality around the lake in 2010, in which the first is the real scheme, the second is the inflow flux multiplier scheme around the lake, and the last is Wangyu River inflow flux multiplier scheme. EcoTaihu Model is adopted to simulate the nutrients conditions in Lake Taihu and its subzones. The results show that under the hydrological, meteorological and the boundary conditions in 2010, an appropriate hydraulic retention time of Lake Taihu is between 150 days and 160 days.

Keywords: Retention time; EcoTaihu Model; Lake Taihu; nutrients flow; eutrophication

换水周期是湖泊水环境的一个重要参数, 影响着水体中污染物与营养物的浓度与停留时间, 以及水体 中发生的生物与化学反应过程时间长短 ${ }^{[1-3]}$. 国内外学者对换水周期展开了大量研究, 如梁乃杰等 ${ }^{[4]}$ 推导建 立了杭州西湖换水的数学模型, 得到水质浓度的变化随引水量的增加而呈负指数的规律减少, 并用电阻率 法对西湖换水过程进行了监测验证. 朱春龙等 ${ }^{[5]}$ 基于周边环境连续输人的充分混合的反应器原理及一些简 化假设, 提出了借助周期性地引排换水改善城市湖泊水质的数学模型, 导出了城市湖泊中污染物平均浓度 和水质改善指标的解析表达式. 郭武等 ${ }^{[6]}$ 结合湘阴县河湖连通工程规划对原有广泛使用的生态流量及水体

* 国家自然科学基金项目(51409049)资助. 2016-03-09 收稿;2016-06-17 收修改稿. 王冼民 (1974 ), 女,副教 授; E-mail: xianmin810@163.com. 
交换公式进行论证,在此基础上建立了基于水质、水量联合调度的生态流量及水体交换周期计算公式,并在 湘阴县河湖水体连通工程中进行了应用验证.

Hatcher 等 ${ }^{[7]}$ 的研究表明, 水体内铵浓度的长期均值与更替周期具有很好的相关性, 在某一范围内湖泊 的更替周期与浮游生物的数量之间存在线性相关关系. 在人湖水体水质良好情况下, 更替周期过长或过短, 都会对湖泊水生态环境产生不利影响, 更替周期过长, 致使污染物在水体中逐渐累积, 水体自净能力下降; 周期过短, 又会冲淡营养物, 不利于水生生物的生长. 在人湖水体水质恶劣情况下, 更替周期过长或过短, 同 样会产生不利影响, 更替周期过短, 会使湖泊内水体直接遭到入湖恶劣水体的替换, 不利于湖泊生物生长; 周期过长会导致水质在空间上存在较大的差异性, 虽然有利于污染物在湖泊内的降解, 但由于蒸发、下渗等 原因, 会造成湖泊水量贵乏、盐度提高, 同时减弱湖泊水动力, 不利于湖泊溶解氧浓度提高和动力扰动适应 性较强生物的生长, 因此存在一个阈值问题, 只有在阈值范围内水体内的生态环境才是最适的. 故更替周期 是研究湖泊水体环境的一个指标,对其阈值的研究,可为建立良好的水生态环境提供依据.

太湖是我国的第三大浅水湖泊, 目前面临着严重的富营养化危机 ${ }^{[8-12]}$, 为缓解太湖水环境危机, 水利部太 湖流域管理局会同流域内有关省市自 2002 年起实施通过望虞河等引长江水人太湖流域的调水工程——“引 江济太”. 多年来, “引江济太”调活了太湖流域水体, 增加了水资源有效供给, 促进了河网有序流动, 改善了太 湖及河网水环境 ${ }^{[13]}$, 为了更好地理解换水周期和望虞河引水对太湖生态环境的影响, 本文利用 EcoTaihu 模型 分析了 3 种情景模式下太湖的换水周期以及各湖区营养盐的变化, 以期为太湖的富营养化治理提供技术支持.

\section{1 材料与方法}

\section{1 太湖历年换水周期}

水量资料采用水利部太湖流域管理局历年整编的逐日径流量统计出逐年出湖水量,依据公式:

换水天数 $=$ 湖泊容积 $\left(\mathrm{m}^{3}\right) /$ 年度出湖水量 $\left(\mathrm{m}^{3}\right) \times 365$

计算得到太湖 1989-2010 年历年换水周期. 其中, 1999 年换水周期最短, 为 $119 \mathrm{~d} ; 1994$ 年换水周期最长, 为 $252 \mathrm{~d}$, 太湖多年平均换水周期为 $192 \mathrm{~d}$. 换水周期与出湖水量密切相关 (图 1), 二者之间的关系为:

$$
y=453.03977-4.01448 x+0.0125 x^{2}
$$

式中, $y$ 为换水周期, $x$ 为出湖水量, 二者相关系数平方值达到 0.989 .

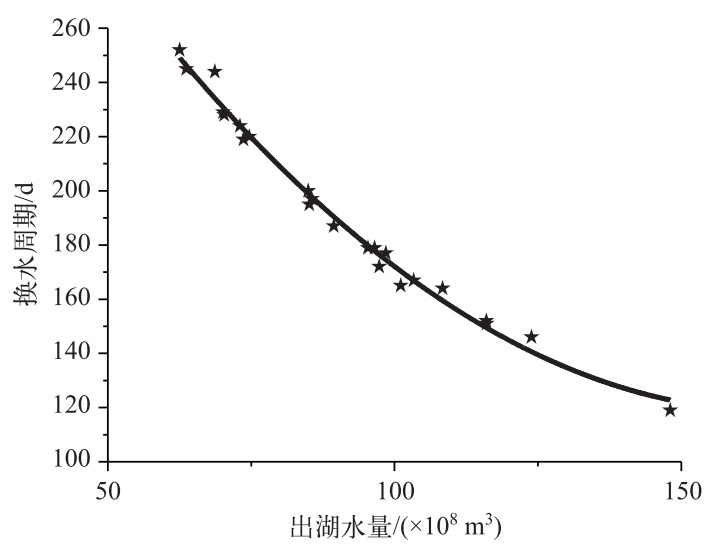

图 1 太湖出湖水量-换水周期的关系

Fig.1 Relationship of out flux and retention time of Lake Taihu

\section{2 太湖适宜换水周期定义及计算方案设计}

根据前文分析, 换水周期对太湖水质变化具有重要影响, 可能存在一个与人湖水量、水质相关的换水天 数, 该换水天数使得太湖水质在特征风场和特定人湖水质条件下处于最优状态, 该换水天数即为适宜换水 周期.

氮、磷是影响太湖水质状况和富营养化以及藻类水华的主要因素 ${ }^{[16-18]}$, 因此本次研究选定氮、磷浓度为 
研究太湖适宜换水周期的指标, 为分析换水周期对太湖水环境的影响, 本文设计了 3 组情景模式. 第 1 组为 实况模式,自 2002 年实施“引江济太”以来, 2002-2010 年期间人湖量最大、最小以及平均值对应年份分别 为 $2010 、 2006$ 以及 2008 年. 因此, 本文实况情景设计采用 2006 、2008 以及 2010 年. 第 2 组为太湖 2010 年人 湖水质浓度不变条件下的环湖河道水量倍比缩放方案 (简称 2010 年环湖河道水量倍比缩放方案). 由于 “引 江济太”主要通过望虞河实施, 因此第 3 组方案为望虞河流量倍增方案. 本文基于 EcoTaihu 模型, 对太湖水 质状况进行模拟计算分析, 并通过模拟水质结果的对比分析太湖水质对换水天数的响应关系, 从而确定太 湖适宜换水周期. 以下为各组方案的详细介绍:

第 1 组为实况出人湖水量、水质条件下的计算方案 (简称实况方案), 表 1 中的 $\mathrm{A} 1 、 \mathrm{~A} 2 、 \mathrm{~A} 3$ 分别代表 $2006 、 2008$ 和 2010 年实况人湖水量、水质.

第 2 组为太湖 2010 年人湖水质浓度不变条件下的环湖河道水量倍比缩放方案 (简称 2010 年环湖河道 水量倍比缩放方案). 假设各河道人湖水质不发生变化, 出湖水质随湖泊水质变化而变化, 各方案中降雨、蒸 发、水源地区取水量、藻类水华量和太湖水位年变化规律保持不变,各河道人湖水量占总河道人湖水量比例 和各河道出湖水量占总河道出湖水量的比例保持不变. EcoTaihu 模型中相关出入湖河道流量计算方法 如下:

设 $Q_{\mathrm{in} i}^{j}$ 为 $j$ 数值试验方案河道 $i$ (直湖港、武进港、雅浦港、太滆运河漕桥河、殷村港、沙塘港桥、大浦、大 港桥、长兴、杨家埠、杭长桥、三里桥、幻溇段、联湖桥南段、太浦河、联湖桥北段、瓜泾口、胥口、湤光运河、望 虞河、华庄、梁溪河、大渲河泵站) 的人湖水量, $Q_{\text {out } i}{ }^{j}$ 为 $j$ 数值试验方案河道 $i$ (直湖港、武进港、雅浦港、太滆 运河漕桥河、殷村港、沙塘港桥、大浦、大港桥、长兴、杨家埠、杭长桥、三里桥、幻溇段、联湖桥南段、太浦河、 联湖桥北段、瓜㳗口、胥口、吘光运河、望虞河、华庄、梁溪河、大渲河原站)的出湖水量.

$$
Q_{\text {in } i}{ }^{j}=r_{j} \cdot Q_{\text {in } i}{ }^{1}
$$

式中, $r_{j}$ 为表 1 中 B1 $\sim$ B 4 人湖水量倍增系数, 分别为 $0.6,0.8 、 1.2$ 和 1.5 倍, 按方案设定原则, 河道出湖水量 可表示为:

$$
Q_{\text {out } i}{ }^{j}=\left(r_{j} \cdot \sum_{l=1}^{23} Q_{\text {in } l}{ }^{1}-Q_{\text {取水 }}-Q_{\text {暴发 }}+Q_{\text {降水 }}-Q_{\text {库容变化 }}\right) Q_{\text {out } i}{ }^{l} / \sum_{l=1}^{23} Q_{\text {out } l}{ }^{1}
$$

根据换水周期定义, 方案 B1 B B 太湖换水天数分别为 2010 年实况换水天数的 $5 / 3 、 1.25 、 5 / 6$ 和 $2 / 3$ 倍.

表 1 不同情景设计模式下的太湖换水周期

\begin{tabular}{|c|c|c|c|c|c|c|c|c|c|c|c|c|c|}
\hline & \multicolumn{3}{|c|}{ 第一组 } & \multicolumn{4}{|c|}{ 第二组 } & \multicolumn{6}{|c|}{ 第三组 } \\
\hline & A1 & A2 & A3 & B1 & B2 & B3 & B4 & $\mathrm{C} 1$ & C2 & C3 & C4 & C5 & C6 \\
\hline 太湖蓄量 $/\left(\times 10^{8} \mathrm{~m}^{3}\right)$ & 44.9 & 48.4 & 47.2 & 47.2 & 47.2 & 47.2 & 47.2 & 47.2 & 47.2 & 47.2 & 47.2 & 47.2 & 47.2 \\
\hline 出湖水量 $/\left(\times 10^{8} \mathrm{~m}^{3}\right)$ & 73.07 & 116.01 & 103.33 & 62.0 & 82.7 & 124.0 & 155.0 & 99.33 & 101.33 & 105.33 & 108.33 & 111.33 & 113.33 \\
\hline 换水周期/d & 224 & 152 & 167 & 277.9 & 208.3 & 138.9 & 111.1 & 173.4 & 170.0 & 163.6 & 159.0 & 154.7 & 152.0 \\
\hline
\end{tabular}

Tab.1 Retention time of Lake Taihu under different scenarios

第 3 组为在 2010 年出人湖水量与水质条件下的望虞河水量倍比缩放方案 (简称 2010 年望虞河水量倍 比缩放方案). 根据 2008-2011 年的引水期望虞河干流望亭立交闸人太湖水质监测资料, 望虞河引江人湖 水质总体优于其他环太湖主要人湖河流水质, 其中高锰酸盐指数年均浓度为 $3.20 \mathrm{mg} / \mathrm{L}$ 、总磷年均浓度为 $0.12 \mathrm{mg} / \mathrm{L}$, 均达到 II 类水标准, 氨氮年均浓度为 $0.54 \mathrm{mg} / \mathrm{l}$, 为 III 类水标准, 但浓度值已接近 II 类水标准, 总 氮年均浓度为 $2.79 \mathrm{mg} / \mathrm{L}$. 在环太湖人湖河流中, 除楚东苕溪、西苕溪水质与望虞河人湖水质持平或略好于 望虞河人湖水质外, 望虞河引江人湖水质均优于其他人太湖河流, 尤其是湖西区人湖河道水质, 望虞河引江 人湖水对改善太湖水环境提供了重要的优质水源.

为充分发挥望虞河 “引江济太”对太湖水质的改善作用,出人湖水量水质情景设计方案为: 基于 2010 年 望虞河引水流量 $10 \times 10^{8} \mathrm{~m}^{3}$, 保持流域降雨、蒸发、取水和库容不变, 通过改变望虞河人湖和太浦河出湖流 量, 影响太湖水体换水时间, 设置 6 个方案: 望虞河引水流量分别为 2010 年实况流量的 $0.6 、 0.8 、 1.2 、 1.5 、 1.8$ 和 2.0 倍,水质为 2010 年实况水质, 分别为表 1 中的 C1 C6. 太浦河出湖水量增减与望虞河水量相当. 


\subsection{EcoTaihu 数值模型}

本次换水周期对太湖水质的影响研究采用 EcoTaihu 模型 ${ }^{[13-15]}$,模型在开发过程中,集成了 1960 年以来 太湖湖流、水位、水质以及生态系统变化调查、实验资料,特别是 2001 年以来在中国科学院太湖生态系统研 究站监测资料的基础上, 构建了太湖生态环境演变基础数据库, 发展了太湖三维的正压水动力模型. 通过湖 泊水动力、营养盐转化、生物生长、代谢及种群竞争等过程的耦合, 创立了包含湖泊水动力要素 (水位、湖 流)、水质参数(氨氮、硝态氮、亚硝态氮、正磷酸盐磷、底泥可交换态氮、底泥可交换态磷、底泥间隙水溶解性 磷、溶解氧)、生物要素 (浮游植物生物量、浮游动物生物量、鱼类生物量、水生植物生物量、碎屑、浮游植物态 氮、浮游动物态氮、水生植物态氮、鱼类态氮、碎屑态氮、浮游植物态磷、浮游动物态磷、水生植物态磷、鱼类 态磷、碎屑态磷) 等 27 个变量的 “太湖水动力学-富营养化生态模型” EcoTaihu. 运用野外原位实验、定点长 期观测和数值模拟结合方法确定了模型参数.

EcoTaihu 模型状态变量模块见图 2. 模型主要由 3 大模块组成:第 1 块为水动力学湖流、水位变化模拟 模块; 第 2 块为食物链网模拟模块, 包括鱼类、有机碎屑、浮游动物、藻类以及高等水生植物; 第 3 块为物质输 移转化模块, 包括溶解氧输移转化子模块、氮输移转化子块和磷输移转化子模块, 其中氮子模块含有 9 个子 模块, 它们为氨氮、亚硝态盐、硝态氮、碎屑态氮、藻类氮、浮游动物态氮输移转化子模块及鱼类态氮、水生植 物态氮、底泥可交换态氮转化子模块; 磷子模块包含正磷酸盐磷、碎屑态磷、浮游植物态磷、浮游动物态磷输 移转化子模块, 以及水生植物态磷、鱼类态磷、底泥间隙水溶解性磷、底泥可交换态磷子模块, 太湖生态模型 详细说明见参考文献 $[14]$.

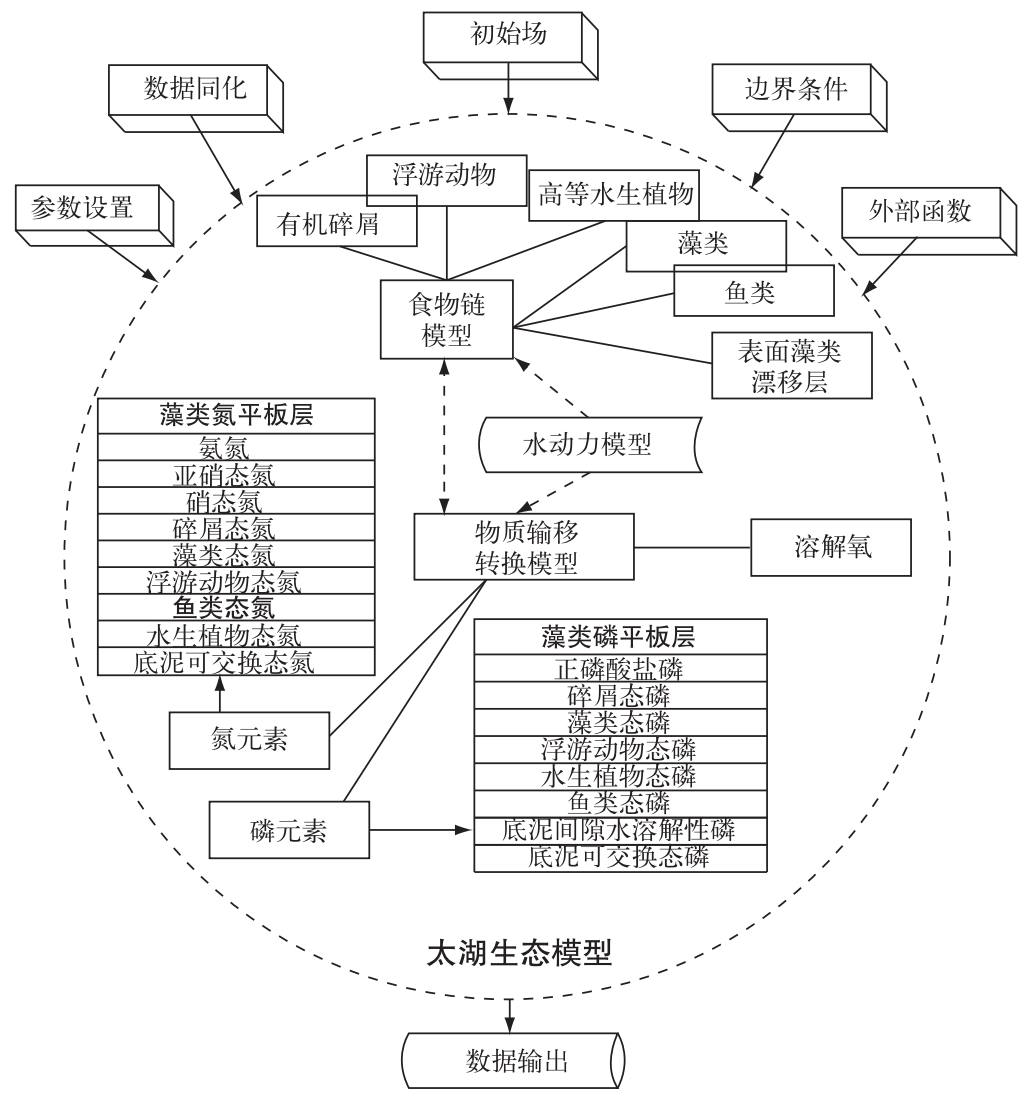

图 2 EcoTaihu 模型模块构成

Fig.2 Structure of EcoTaihu Model 
1.3.1 模型构架 EcoTaihu 模型网格剖分、分区以及 环湖河道见图 3 ,全太湖划分为 $69 \times 69$ 个矩形网格, 网格边长为 $1000 \mathrm{~m} \times 1000 \mathrm{~m}$, 共有活动单元 2338 个. 计算时间步长设置为 $120 \mathrm{~s}$. 考虑到太湖空间异质 性, 将太湖分为 8 个区, 分别是贡湖、梅梁湖、竺山 湖、湖西区、西南区、湖心区、湖东滨岸区以及东太 湖 (图 3). 将从太湖取水的电厂取水口以及水源地 取水口概化为边界条件予以考虑, 将其概化为出湖 河道. 环湖河道共概化为 33 条, 1 33 分别为小湾 里水源地、大渲河洜站、梁溪河、直湖港、武进港、沙 塘港、太滆运河漕桥河、殷村港、雅浦港、大浦、大港 河、长兴、杨家埠、杭长桥、幻溇段、三里桥河段、嘉 兴水源地、联湖桥北段、庙港水源地、太浦河、联湖 桥南段、瓜泾港、浦前水源地、胥江、渔洋山水源地、 吘光运河、镇湖水源地、金墅湾水源地、望虞河、锡 东水源地、华庄河、望亭电厂取水口和南泉水源地 (图 3). 2010 年计算的外部条件设置见图 4.

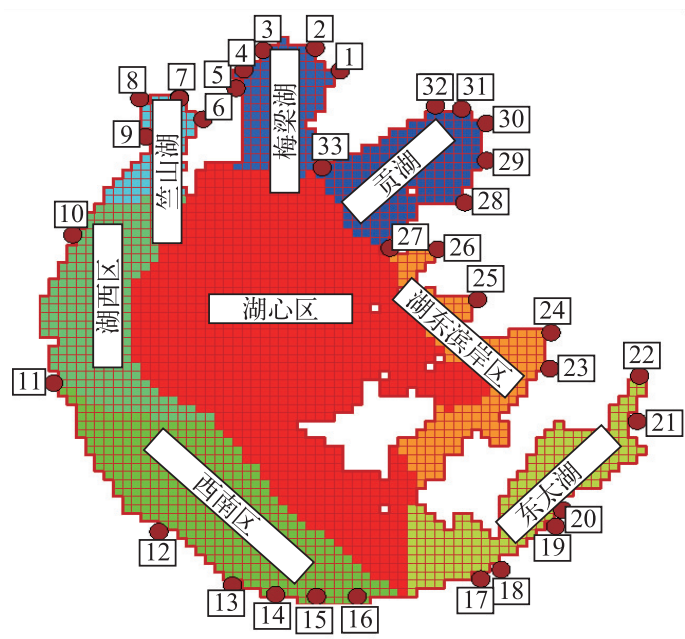

图 3 EcoTaihu 模型网格剖分、分区以及环湖河道

Fig.3 Grid setup, zone division and inflow-outflow of EcoTaihu Model
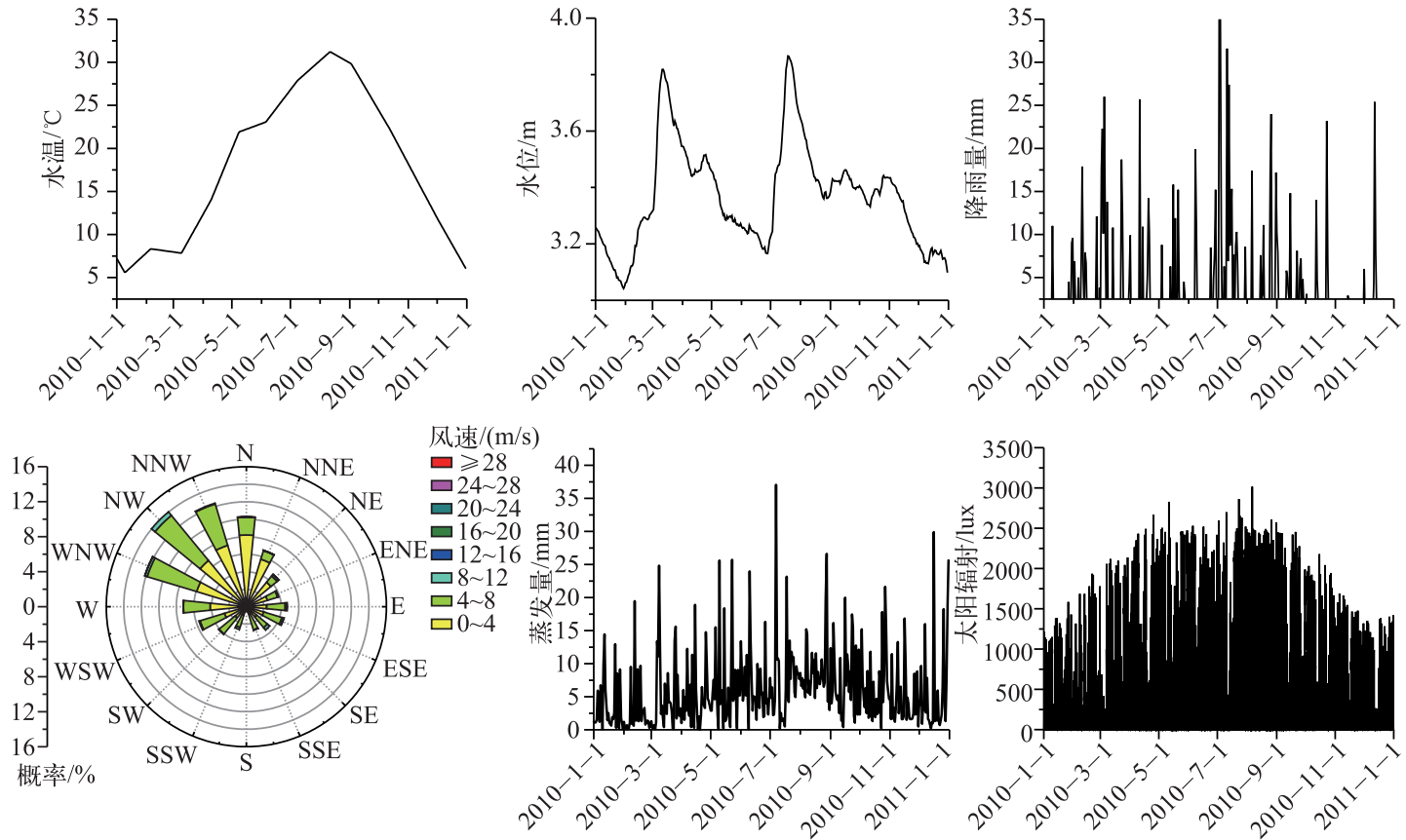

图 4 模型计算外部条件

Fig.4 External conditions of model simulation

1.3.2 模型参数 模型参数在模型计算中具有重要地位,EcoTaihu 模型参数共分为水动力、营养元素氮磷、浮 游动植物、沉水植物、鱼类、有机碎屑等 6 个方面内容, 限于篇幅, 表 2 中仅列出营养元素氮、磷方面的相关参 数, 详细参数设置见参考文献 [14-15].

1.3 .3 模型验证 基于 2010 年水文、气象监测资料,开展了太湖在湖面非均匀风场作用下太湖水体营养盐 氮、磷含量、以及溶解氧含量的数值模拟, 并用水利部太湖流域管理局无锡水文监测局太湖常规监测站点小 湾里、渔业村、龙头、贡湖、庙港、饯港外、湖心南、胥湖、横山、梅园、问江口、竺山湖、大浦、伏东、焦山、拖山、 
表 2 营养盐氮、磷参数取值

Tab.2 Parameters of nitrogen and phosphorus

\begin{tabular}{|c|c|c|}
\hline 参数名称 & 单位 & 取值 \\
\hline 亚硝态氮氧化的最低溶解氧浓度 & $\mathrm{mg} / \mathrm{L}$ & 1.5000 \\
\hline 亚硝态氮氧化时溶解氧的半饱和常数 & $\mathrm{mg} / \mathrm{L}$ & 3.0000 \\
\hline $20^{\circ} \mathrm{C}$ 时亚硝态氮的氧化速率 & $1 / \mathrm{d}$ & 1.0000 \\
\hline 氨氮氧化的最低溶解氧浓度 & $\mathrm{mg} / \mathrm{L}$ & 2.0000 \\
\hline 氨氮氧化时溶解氧的半饱和常数 & $\mathrm{mg} / \mathrm{L}$ & 4.0000 \\
\hline $20^{\circ} \mathrm{C}$ 时氨氮的氧化速率 & $1 / \mathrm{d}$ & 0.1200 \\
\hline 底泥氮释放速率 & $1 / \mathrm{d}$ & $10^{-6}$ \\
\hline 温度影响亚硝态氮氧化系数 1 & - & 1.1000 \\
\hline 温度影响亚硝态氮氧化系数 2 & - & 1.2000 \\
\hline 温度影响氨氮氧化系数 1 & - & 1.0650 \\
\hline 温度影响氨氮氧化系数 2 & - & 1.2000 \\
\hline 碎屑态氮氧化的半饱和常数 & - & 0.1510 \\
\hline 温度影响底泥氮释放的系数 & - & 0.00755 \\
\hline 温度影响底泥可交换态磷矿化系数 & - & 1.1300 \\
\hline $20^{\circ} \mathrm{C}$ 时可溶解性磷的氧化速率 & $1 / \mathrm{d}$ & 1.0000 \\
\hline 溶解氧对间隙水溶解性磷的扩散影响系数 & - & 6.0000 \\
\hline 温度对底泥间隙水磷释放的影响系数 & - & 0.01 \\
\hline 底泥间隙水溶解性磷的释放速率 & $1 / \mathrm{d}$ & 0.000500 \\
\hline 溶解氧对间隙水溶解性磷释放的影响系数 & - & 0.5000 \\
\hline 溶解氧浓度大于 1 mg/L 的碎屑转化为可交换态磷的比率 & - & 0.800000 \\
\hline 底泥可交换态磷矿化速率 & $1 / \mathrm{d}$ & 0.000035 \\
\hline 溶解氧浓度小于 $1 \mathrm{mg} / \mathrm{L}$ 的碎屑转化为可交换态磷的比率 & - & 0.600000 \\
\hline
\end{tabular}

三号标、乌龟山、大贡山、沙墩港、平台山、14 号标、夹浦、新塘、小梅口、大钱、西山、胥口、漫山和东太湖等 30 个监测点实测值进行模型检验.

2010 年所有监测点预测的总磷年相对误差为 $47 \%, 16$ 个监测点的相对误差小于 $40 \%$; 贡湖、胥湖、乌龟 山、大公山、胥口、漫山监测点的相对误差较高, 超过了 $50 \%$. 所有监测点预测的总氮年相对误差为 $39 \%$, 其 中 20 个监测点的相对误差小于 $40 \%$. 庙港、刬港外、平台山、小湾里、大钱、东太湖监测点的相对误差超 过 $50 \%$.

总体而言, 藻型湖区如西太湖和竺山湖等, 模型计算值和实测值较为一致, 如龙头、竺山湖、夹浦、新塘 等监测点. 而水生植物生长较为旺盛的湖区, 如西山、东太湖等监测点, 计算值和实测值的差异相对较大一 些, 这可能与水生植物吸收氮、磷的速率有关系. 除小湾里、胥湖、梅园、问江口、大浦、西山、东太湖等监测点 平均相对误差较大以外, 其余监测点模拟效果较好, 且大多数监测点的模拟计算结果的变化趋势与实测值 一致, 模型能较好地描述水体中氮、磷的变化(图 5,6).

\section{2 结果与讨论}

\section{1 各计算方案不同湖区换水周期}

换水周期计算采用式 (1): 即太湖 (每个湖区) 的容积除以出湖 (区) 水量为太湖 (各湖区) 的换水周期. 计算结果表明, 梅梁湖区因直湖港节制闸的作用, 由直湖港进人的水体减少, 因此其水体换水时间较长. 按 梅梁湖湾口断面与大太湖水量交换计算, 换水时间最长. 西南区通过控制断面水量交换计算得到的换水时 间也很长, 由于贡湖为引江调水的通道、东太湖为出水通道, 它们换水速率远高于其他区域, 相应的水体换 水时间也较短. 竺山湖和湖西区因不位于换水主流线上, 其水体换水时间基本未发生变化. 另外湖东滨岸及 湖心区换水速率变化幅度也较小 (表 3 ). 

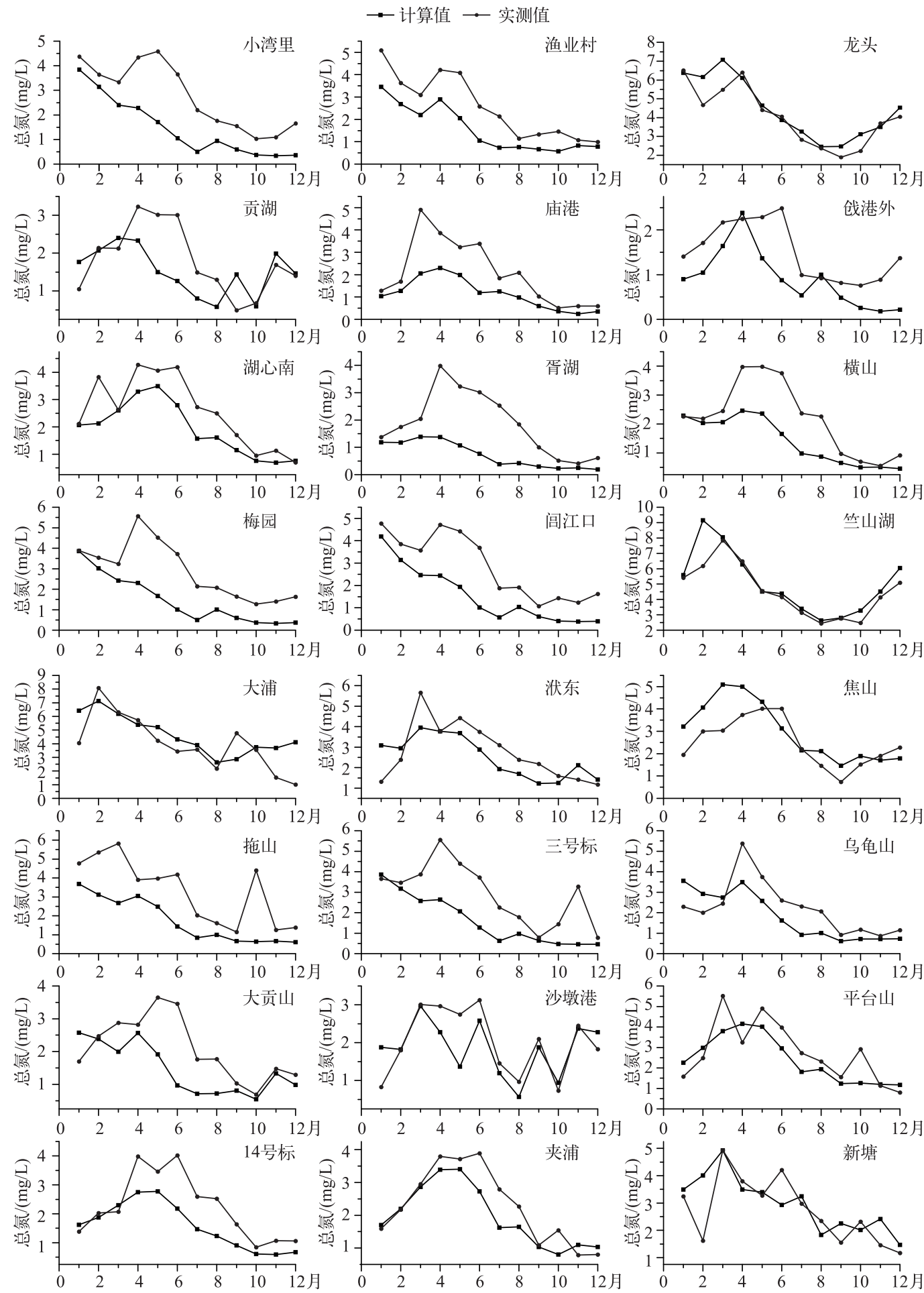

图 52010 年各监测点总氮实测值和计算值

Fig.5 Observation data and simulation data of total nitrogen concentration in each watch spot in 2010 

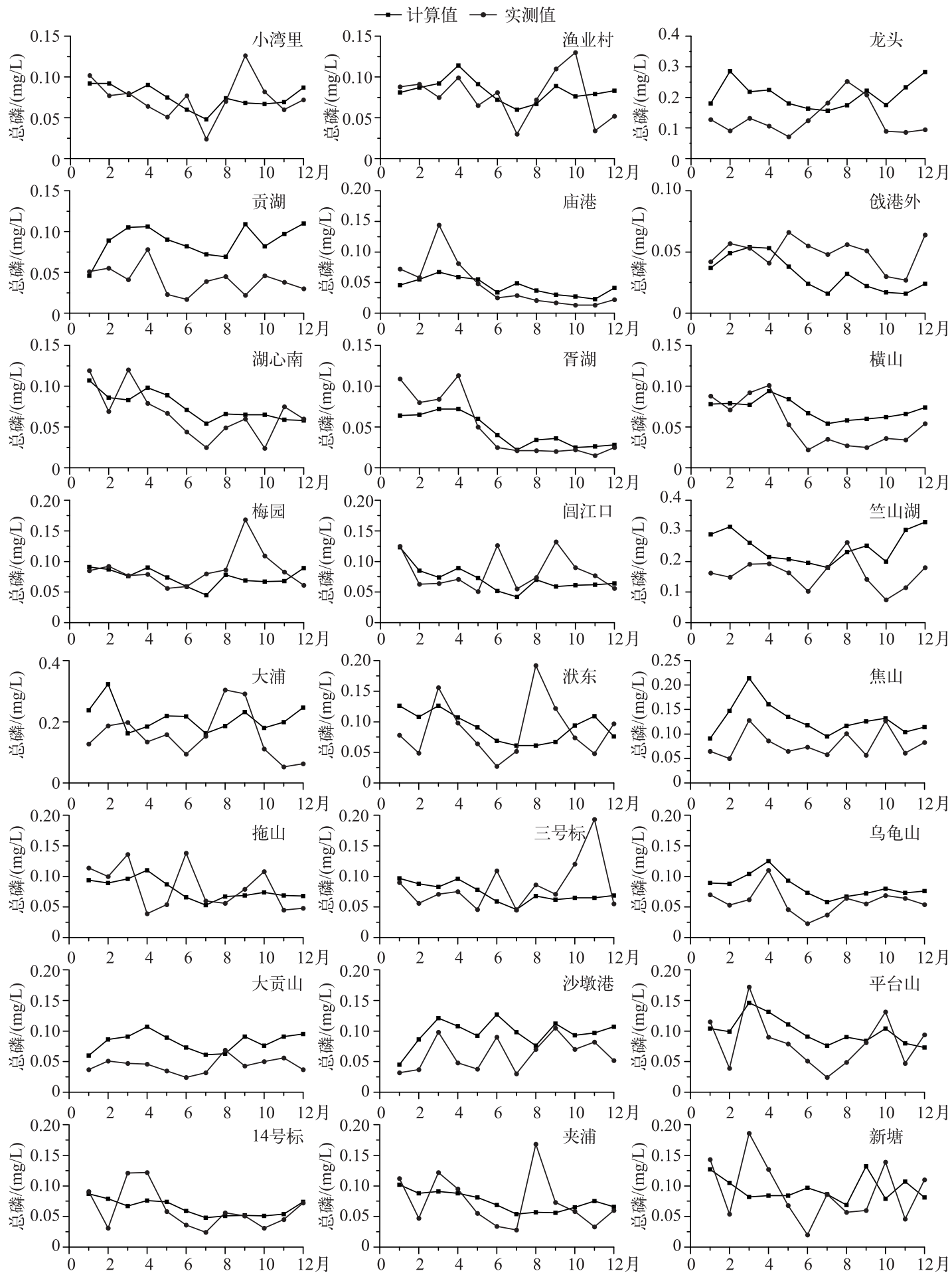

图 62010 年各监测点总磷实测值和计算值

Fig.6 Observation data and simulation data of total phosphorus concentration in each watch spot in 2010 
表 3 各计算方案不同湖区水体换水周期

Tab.3 Retention time of subzones of Lake Taihu under different scenarios

\begin{tabular}{lcccccccc}
\hline \multirow{2}{*}{ 方案 } & \multicolumn{7}{c}{ 换水周期/d } \\
\cline { 2 - 10 } & 梅梁湾 & 贡湖 & 湖东区 & 东太湖 & 竺山湖 & 湖西区 & 西南区 & 湖心区 \\
\hline A1 & 360.1 & 56.9 & 135.7 & 23.6 & 61.3 & 75.3 & 163.6 & 100.5 \\
A2 & 352.3 & 49.1 & 131.9 & 19.7 & 60.1 & 72.6 & 145.8 & 93.6 \\
A3 & 349.6 & 46.5 & 130.3 & 18.1 & 59.8 & 71.3 & 136.7 & 91.2 \\
B1 & 626.6 & 77.8 & 233.2 & 31.1 & 100.8 & 122.9 & 249.2 & 164.0 \\
B2 & 457.3 & 60.6 & 164.7 & 23.7 & 79.8 & 94.2 & 186.6 & 114.7 \\
B3 & 294.8 & 42.5 & 119.2 & 15.5 & 51.2 & 62.3 & 118.1 & 81.3 \\
B4 & 255.9 & 32.0 & 89.8 & 13.1 & 40.9 & 51.7 & 94.9 & 63.6 \\
C1 & 362.2 & 59.7 & 136.9 & 22.9 & 61.9 & 75.6 & 163.9 & 101.7 \\
C2 & 354.7 & 52.2 & 132.4 & 20.3 & 60.1 & 73.2 & 153.8 & 96.5 \\
C3 & 341.7 & 41.9 & 129.7 & 15.9 & 58.1 & 70.9 & 131.7 & 89.0 \\
C4 & 323.9 & 35.1 & 126.1 & 14.1 & 57.6 & 68.5 & 125.5 & 86.3 \\
C5 & 315.6 & 31.4 & 124.5 & 12.6 & 56.5 & 67.1 & 116.1 & 83.5 \\
C6 & 302.6 & 27.3 & 121.9 & 11.4 & 55.9 & 66.7 & 105.7 & 81.3 \\
\hline
\end{tabular}

\section{2 各计算方案不同湖区水质变化情况}

2.2.1 A 方案 (实况方案) 代表年太湖各湖区水质中竺山湖和梅梁湖水质最差, 竺山湖水质差是因为人湖 河道水质较差, 且竺山湖湖区面积较小, 缓冲能力较弱, 竺山湖水体水质直接决定于入湖河道水质. 另外, 由 于马山的阻挡, 望虞河调水对其水质改善作用有限. 梅梁湖主要是因为水体换水时间较长, 和大太湖水量交 换不畅,夏季东南风作用下污染物和藻类进入梅梁湖后难以流出, 导致湖区水体水质恶化. 通过 “引江济 太”, 梅梁湖和贡湖水质改善最为明显. 各湖区中水质最好的是东太湖, 其次为西南区和湖东滨岸区. 从各个 季节来看,各湖区夏季水质较好、冬季最差. 2006 、2008 以及 2010 年太湖总氮计算均值为 $2.72 、 2.51$ 和 2.48 $\mathrm{mg} / \mathrm{L}$, 太湖总磷计算均值为 $0.12 、 0.063$ 和 $0.071 \mathrm{mg} / \mathrm{L}$. 换水时间为: 2006 年 $>2008$ 年 $>2010$ 年, 实况水质为: 2006 年 $<2008$ 年 $<2010$ 年. 这是因为自 2008 年开始, 太湖进行了大规模环境治理以及蓝藻打捞, 同时 “引江 济太”规模也不断增大. 说明换水周期只是影响湖泊水质的一个因素.

2.2.2 B 方案 (2010 年环湖河道水量倍比缩放方案)

1) 对竺山湖和湖西区的影响

竺山湖和湖西区人湖河流水质最差, 因此, 在保持 2010 年人湖河道水质不变, 水量倍比方案下, 人湖水 量越小,水质越好. B1 方案 ( 0.6 倍) 中竺山湖和湖西区总氮平均计算浓度分别为 4.26 和 $2.87 \mathrm{mg} / \mathrm{L}$, 总磷平 均浓度为 0.149 和 $0.126 \mathrm{mg} / \mathrm{L}$. 在 1.5 倍水量条件下, 竺山湖和湖西区总氮平均计算浓度值分别升为 6.87 和 $3.75 \mathrm{mg} / \mathrm{L}$, 总磷平均浓度为 0.27 和 $0.19 \mathrm{mg} / \mathrm{L}$. 这说明改善竺山湖和湖西区的水质主要需要控制污染源的 流人.

2) 对湖心区的影响

湖心区在太湖 8 个分区中面积最大, 是太湖人湖污染物出湖的主要缓冲区. 竺山湖以及湖西区的重污 染水体经过湖心区净化, 从太湖东部流出, 此外, 从望虞河以及太湖西南部湖区进人的水质较好, 水体起着 净化湖心区的作用, 因此, 湖心区水质主要取决于进人该区水体的清污比. 在倍比条件下, 清污比不变, 进人 湖心区的污染物越少, 湖心区水质越好. 2010 年在 0.6 倍人湖水量条件下, 湖心区总氮平均计算浓度为 2.65 $\mathrm{mg} / \mathrm{L}$, 总磷平均浓度为 $0.090 \mathrm{mg} / \mathrm{L}$. 在 1.5 倍水量条件下, 湖心区总氮平均计算浓度升为 $3.23 \mathrm{mg} / \mathrm{L}$, 总磷平 均浓度为 $0.11 \mathrm{mg} / \mathrm{L}$. 湖心区随水量倍比增幅不如竺山湖和湖西区大, 这一方面是因为进入湖心区的水体水 质较好,另外一方面是湖心区面积较大,具有较强的自净能力.

3) 对西南区的影响

浙西人湖水体水质通常相对较好, 望虞河人湖水质与浙西人湖水体水质相当, 东苕溪、西苕溪水质与望 
虞河人湖水质持平或略好于望虞河人湖水质. 因此西南区水质也较好, 主要受湖心区和湖西区进人污水的 影响, 由于湖心区和湖西区随水量倍比增加水质变差, 西南区水质也随之变差, 2010 年在 0.6 倍人湖水量条 件下, 西南区总氮平均计算浓度为 $2.09 \mathrm{mg} / \mathrm{L}$, 总磷平均浓度为 $0.059 \mathrm{mg} / \mathrm{L}$. 在 1.5 倍水量条件下, 西南区总 氮平均计算浓度升为 $2.43 \mathrm{mg} / \mathrm{L}$, 总磷平均浓度为 $0.072 \mathrm{mg} / \mathrm{L}$.

4) 对贡湖和梅梁湖的影响

水量倍增各方案对贡湖和梅梁湖的影响比较复杂, 在春季和夏季东南风作用下, 大量太湖蓝藻随风生 流漂流到贡湖和梅梁湖区, 望虞河调水水质较好, 随望虞河流量的增大, 可以起到抬高贡湖水位, 抑制污水 流向贡湖以及冲散蓝藻、改善湖区水质的作用, 但是当环湖水量增大时, 湖心区的水质随之恶化,大量水质 差的水体随之进入贡湖和梅梁湖湖区. 梅梁湖和贡湖水质在 B3 方案下 (1.2 倍水量) 水质最好, 梅梁湖和贡 湖总氮平均计算浓度分别为 4.81 和 $1.96 \mathrm{mg} / \mathrm{L}$, 梅梁湖和贡湖总磷平均计算浓度值分别为 0.153 和 0.181 $\mathrm{mg} / \mathrm{L}$.

5) 对东太湖和湖东滨岸区的影响

东太湖和湖东滨岸区是太湖水质最好的两个区. 其中东太湖也是太湖主要的出水口. 两个区分布着大 量的水生植物, 对水体的净化能力较强. 东太湖和湖东滨岸区水质主要受湖心区进人水体的影响, 湖心区随 着水量倍比增加水质变差, 东太湖和湖东滨岸区水质也随之变差, 2010 年在 0.6 倍人湖水量条件下, 东太湖 和湖东滨岸区总氮平均计算浓度分别为 1.39 和 $1.59 \mathrm{mg} / \mathrm{L}$, 总磷平均浓度分别为 0.041 和 $0.040 \mathrm{mg} / \mathrm{L}$. 在 1.5 倍水量条件下, 东太湖和湖东滨岸区总氮平均计算浓度升为 1.62 和 $1.85 \mathrm{mg} / \mathrm{L}$, 总磷平均浓度为 0.062 和 $0.078 \mathrm{mg} / \mathrm{L}$.

6) 对太湖的影响

各倍比方案进人太湖的污水和清水比例不变, 进人太湖的水量越大, 则进人太湖的污染物越多, 因此计 算方案中 0.6 倍环湖水量条件下太湖水质最好, 总氮平均浓度为 $2.41 \mathrm{mg} / \mathrm{L}$, 总磷平均浓度为 $0.069 \mathrm{mg} / \mathrm{L}$, 1.5 倍环湖水量条件下太湖水质最差, 总氮平均浓度为 $3.1 \mathrm{mg} / \mathrm{L}$, 总磷平均浓度为 $0.093 \mathrm{mg} / \mathrm{L}$.

2.2.3 C 方案 ( 2010 年望虞河水量倍比缩放方案)

1)对竺山湖和湖西区的影响

望虞河调水引人水质好的水体可改善竺山湖以及湖西区的水质, 调水越多, 改善越大, 但由于竺山湖和 湖西区不在调水线路的主线上, 因此对水质改善程度有限, 2010 年 0.6 倍望虞河人湖水量条件下, 竺山湖和 湖西区总氮平均计算浓度分别为 5.46 和 $3.38 \mathrm{mg} / \mathrm{L}$, 总磷平均浓度为 0.174 和 $0.159 \mathrm{mg} / \mathrm{L}$, 在 1.5 倍水量条 件下, 竺山湖和湖西区总氮平均计算浓度改善为 5.01 和 $3.04 \mathrm{mg} / \mathrm{L}$, 总磷平均浓度为 0.142 和 $0.136 \mathrm{mg} / \mathrm{L}$, 当 望虞河水量增大到 2.0 倍时, 竺山湖和湖西区总氮平均计算浓度改善为 4.97 和 $3.01 \mathrm{mg} / \mathrm{L}$, 总磷平均浓度为 0.141 和 $0.132 \mathrm{mg} / \mathrm{L}$. 说明当望虞河水量增大到 1.5 倍后, 再增大水量对竺山湖和湖西区水质改善作用不大.

2) 对湖心区的影响

望虞河进人的水质较好的水体起着净化湖心区水体的作用,通过望虞河调水,可改善湖心区清污比,望 虞河调水越多,湖心区水质改善越明显, 2010 年在 0.6 倍望虞河人湖水量条件下,湖心区总氮平均计算浓度 为 $3.01 \mathrm{mg} / \mathrm{L}$, 总磷平均浓度为 $0.103 \mathrm{mg} / \mathrm{L}$. 在 1.5 倍水量条件下, 湖心区总氮平均计算浓度改善为 $2.46 \mathrm{mg} / \mathrm{L}$, 总磷平均浓度为 $0.086 \mathrm{mg} / \mathrm{L}$. 望虞河水量增大到 2.0 倍时, 湖心区总氮平均计算浓度改善为 $2.41 \mathrm{mg} / \mathrm{L}$, 总磷 平均浓度为 $0.084 \mathrm{mg} / \mathrm{L}$.

3 ) 对西南区的影响

西南区水质主要受湖心区和湖西区进人污水的影响, 由于湖心区和湖西区随水量倍比增加水质变差, 西南区水质也随之变差, 但西南区不在望虞河调水的主线路上, 因此望虞河调水对其水质改善影响不大. 2010 年在 0.6 倍望虞河人湖水量条件下, 西南区总氮平均计算浓度为 $2.31 \mathrm{mg} / \mathrm{L}$, 总磷平均浓度为 $0.061 \mathrm{mg} / \mathrm{L}$. 在 1.5 倍水量条件下, 西南区总氮平均计算浓度改善为 $2.07 \mathrm{mg} / \mathrm{L}$, 总磷平均浓度为 $0.062 \mathrm{mg} / \mathrm{L}$. 当望虞河调水流量为 2.0 倍时, 西南区总氮平均计算浓度改善为 $2.06 \mathrm{mg} / \mathrm{L}$, 总磷平均浓度为 $0.065 \mathrm{mg} / \mathrm{L}$.

4) 对贡湖和梅梁湖的影响

望虞河引水对改善贡湖、梅梁湖湾水质的效果较好. 望虞河引水进人贡湖, 可直接促进贡湖水体流动, 
改善水质作用明显. 得到改善的贡湖水体在东南风的作用下,随湖流流人梅梁湖湾, 可改善梅梁湖水质. 当 望虞河引江人湖流量为 0.6 倍时, 贡湖、梅粱湖总氮浓度分别为 2.45 和 $5.12 \mathrm{mg} / \mathrm{L}$, 贡湖、梅粱湖总磷浓度分 别为 0.085 和 $0.152 \mathrm{mg} / \mathrm{L}$; 当望虞河水量增大为 1.5 倍时, 贡湖、梅粱湖总氮浓度分别为 1.92 和 $4.17 \mathrm{mg} / \mathrm{L}$, 贡湖、梅粱湖总磷浓度分别为 0.083 和 $0.112 \mathrm{mg} / \mathrm{L}$; 当望虞河水量再增大时, 对贡湖和梅梁湖水质改善作用 不大.

$5)$ 对东太湖和湖东滨岸区的影响

在 0.6 倍人湖水量条件下, 东太湖和湖东滨岸区总氮平均计算浓度分别为 1.23 和 $1.70 \mathrm{mg} / \mathrm{L}$, 总磷平均 浓度分别为 0.052 和 $0.047 \mathrm{mg} / \mathrm{L}$. 在 1.5 倍水量条件下, 东太湖和湖东滨岸区总氮平均计算浓度分别为 1.16 和 $1.6 \mathrm{mg} / \mathrm{L}$, 总磷平均浓度分别为 0.056 和 $0.049 \mathrm{mg} / \mathrm{L}$, 总磷浓度出现了小幅上升. 当水量增大到 2.0 倍时, 东太湖和湖东滨岸区总氮平均计算浓度为 1.17 和 $1.61 \mathrm{mg} / \mathrm{L}$, 总磷平均浓度为 0.057 和 $0.051 \mathrm{mg} / \mathrm{L}$.

6) 对太湖的影响

在 0.6 倍人湖水量条件下, 东太湖和湖东滨岸区总氮平均计算浓度为 1.34 和 $1.85 \mathrm{mg} / \mathrm{L}$, 总磷平均浓度 为 0.047 和 $0.052 \mathrm{mg} / \mathrm{L}$. 在 1.5 倍水量条件下, 东太湖和湖东滨岸区总氮平均计算浓度为 1.35 和 $1.41 \mathrm{mg} / \mathrm{L}$, 总磷平均浓度为 0.050 和 $0.059 \mathrm{mg} / \mathrm{L}$. 当水量增大到 2.0 倍时, 东太湖和湖东滨岸区总氮平均计算浓度为 1.38 和 $1.45 \mathrm{mg} / \mathrm{L}$, 总磷平均浓度为 0.053 和 $0.062 \mathrm{mg} / \mathrm{L}$.

\section{3 太湖适宜换水周期分析}

由于太湖实况方案中 2006 与 2008 年人湖河道水质以及气象情况不同. 因此主要分析 A3 组、B 组和 C 组不同换水天数对水质的影响,各组方案换水天数及其对应的氮、磷浓度见表 4.

表 4 各方案中太湖换水周期与总氮、总磷浓度

Tab.4 Retention time of Lake Taihu versus total nitrogen and total phosphorus concentrations under different scenarios

\begin{tabular}{|c|c|c|c|c|c|c|c|c|c|c|c|c|c|}
\hline & \multicolumn{3}{|c|}{ 第一组 } & \multicolumn{4}{|c|}{ 第二组 } & \multicolumn{6}{|c|}{ 第三组 } \\
\hline & $\mathrm{A} 1$ & $\mathrm{~A} 2$ & A3 & B1 & B2 & B3 & B4 & C1 & $\mathrm{C} 2$ & C3 & $\mathrm{C} 4$ & C5 & C6 \\
\hline 换水周期 $/ \mathrm{d}$ & 224 & 152 & 167 & 277.9 & 208.3 & 138.9 & 111.1 & 173.4 & 170.0 & 163.6 & 159.0 & 154.7 & 152.0 \\
\hline 总氮平均浓度 $/(\mathrm{mg} / \mathrm{L})$ & 2.55 & 2.45 & 2.48 & 2.41 & 2.46 & 2.55 & 3.10 & 2.62 & 2.53 & 2.39 & 2.33 & 2.32 & 2.32 \\
\hline 总磷平均浓度/ $(\mathrm{mg} / \mathrm{L})$ & 0.081 & 0.072 & 0.071 & 0.069 & 0.070 & 0.076 & 0.083 & 0.073 & 0.072 & 0.070 & 0.070 & 0.069 & 0.069 \\
\hline
\end{tabular}

从图 7 可以看出, 太湖总氮、总磷浓度都是在换水天数 $150 \sim 160 \mathrm{~d}$ 左右最低. 因此, 2010 年水情、水质条 件下,太湖适宜换水周期为 $150 \sim 160 \mathrm{~d}$.
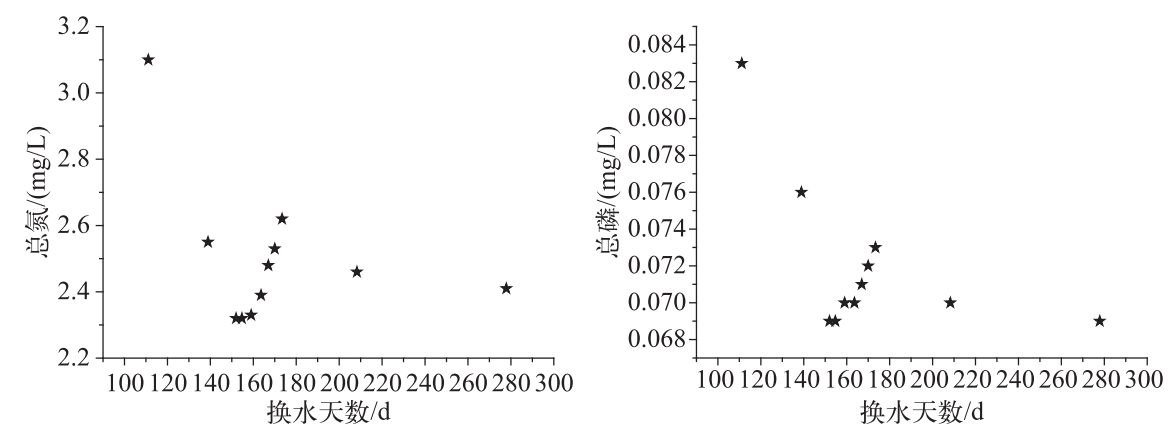

图 7 太湖换水天数与总氮、总磷浓度的关系

Fig.7 Retention time of Lake Taihu versus total nitrogen and total phosphorus concentrations

\section{3 结论}

1) 太湖水质改善效果与引水流量密切相关, 随着引水流量增加, 水质改善效果转好, 但改善效率会随引 
水流量的增加而减小. 当望虞河人湖流量达到 2010 年 1.5 倍时,太湖水质改善程度趋于减小.

2) 望虞河引水改善贡湖、梅梁湖湾水质的效果较好. 望虞河引水进人贡湖, 可直接促进贡湖水体流动, 改善水质作用明显. 得到改善的贡湖水体在东南风的作用下, 随湖流流人梅梁湖湾, 可改善梅梁湖水质. 但 受马山的阻隔影响, 对竺山湖和湖西区作用不明显.

3) 需要指出的是, 通过望虞河引水人太湖, 随着望虞河引水人湖量增大, 太湖西部人湖河道人湖水量将 因太湖水位抬高而减少. 由于太湖西部人湖河道入湖水质远远劣于望虞河人湖水质, 因此实际上望虞河引 水人湖量大还可以减少湖西区重污染水体污染物入湖量. 具体量值需要耦合太湖三维生态模型和太湖流域 河网模型作进一步研究.

4) 通过计算太湖代表年, 环湖河道流量倍比缩放以及望虞河河道流量倍比缩放方案, 研究太湖全湖以 及各湖区的水体换水周期, 比较各代表年数据, 得到 2010 年太湖水质最优, 环湖河道等比缩放为 0.6 倍太湖 水质最优, 望虞河流量倍增方案 1.5 倍最优. 计算得到 $150 \sim 160 \mathrm{~d}$ 换水周期条件下太湖总氮、总磷浓度最低, 即太湖适宜换水周期为 $150 \sim 160 \mathrm{~d}$.

\section{4 参考文献}

[ 1 ] Moore WS, Oliveira J. Determination of residence time and mixing processes of the Ubatuba, Brazil, inner shelf waters using natural Ra isotopes. Estuarine Coastal and Shelf Science, 2008, 3(1) : 512-521.

[ 2 ] Andutta F, Kingsford M, Wolanski E. 'Sticky water' enables the retention of larvae in a reef mosaic. Estuarine Coastal and Shelf Science, 2012, 101(2): 54-63.

[ 3 ] Deleersnijder R, Beckers JM, Delhez EJM. On the behavior of the residence time at the bottom of the mixed layer. Environmental Fluid Mechanics, 2006, 6( 5) : 541-547.

[ 4 ] Liang Naijie, Wei Yulon, Wu Zhichun. The interpretation of the observations on the first water-changing work in the West Lake, Hangzhou. Geophysical \& Geochemical Exploration, 1989, 13(4): 281-289. [梁乃杰, 魏玉轮, 吴志春. 杭州西湖 初次换水观测结果的解释. 物探与化探, 1989, 13(4) : 281-289.]

[ 5 ] Zhu Chunlong, Yu Guoqing. A mathematical model of water quality rehabilitation for urban lakes via periodically water renewal. Journal of Irrigation and Drainage, 2003, 22(6): 54-56. [ 朱春龙, 俞国青. 通过周期性换水更新城市湖泊水 质的解析模型. 灌溉排水学报, 2003, 22(6): 54-56.]

[ 6 ] Guo Wu, Qian Zhan. Aquatic ecology flow and changing water cycle calculation method for Dong Lake in Xiangyin, Hunan. Journal of Central South University of Forestry \& Technology, 2001, 31(9): 66-69. [ 郭武, 钱湛. 湖南湘阴东湖水 体生态流量及换水周期计算方法. 中南林业科技大学学报, 2001, 31(9) : 66-69.]

[ 7 ] Hatcher AI, Frith CA. The control of nitrate and ammonium concentrations in a coral reef lagoon. Coral Reefs, 1985, (4): 101-110.

[ 8 ] Qin BQ, Xu PZ, Wu QL et al. Environmental issues of Lake Taihu, China. Hydrobiologia, 2007, 581(6) : 3-14.

[ 9 ] Zhu Guangwei. Eutrophic status and causing factors of a large, shallow and subtropical Lake Taihu, China. J Lake Sci, 2008, 20 (1) : 21-26.DOI: 10.18307/2008.0103. [ 朱广伟. 太湖富营养化现状及原因分析. 湖泊科学, 2008, 20(1)： 21-26.]

[10] Qin Boqiang, Wang Xiaodong, Tang Xiangming et al. Drinking water crisis caused by eutrophication and cyanobacterial bloom in Lake Taihu: Cause and measurement. Advances in Earth Science, 2007, 22(9) : 896-906. [秦伯强, 王小冬, 汤 祥明等. 太湖富营养化与蓝藻水华引起的饮用水危机一一原因与对策. 地球科学进展, 2007, 22(9): 896-906.]

[11] Chen Xiaofeng, Chuai Xiaoming, Zeng Jin et al. Nitrogenous fluxes and its self-purification capacity in Lake Taihu. Environmental Science, 2012, 33(7) : 2309-2314. [陈小锋, 揣小明, 曾巾等. 太湖氮素出入湖通量与自净能力研究. 环 境科学, 2012, 33(7): 2309-2314.]

[12] Yang Longyuan, Qin Boqiang, Hu Weiping et al. The atmospheric deposition of nitrogen and phosphorus nutrients in Taihu Lake. Oceanologia et Limnologia Sinica, 2007, 38(2): 104-110. [杨龙元, 秦伯强, 胡维平等. 太湖大气氮、磷营养元 素干湿沉降率研究. 海洋与湖沼, 2007, 38(2) : 104-110.]

[13] Hu W, Zhai S, Zhu Z et al. Impacts of the Yangtze River water transfer on the restoration of Lake Taihu. Ecological Engineering, 2008, 34(6) : 30-49.

[14] Hu W, Jørgensen SE, Zhang F. A vertical-compressed three-dimensional ecological model in Lake Taihu, China. Ecologi- 
cal Modelling, 2006, 190(2): 367-398.

[15] Hu Weiping, Qin Boqiang. A three-dimensional numerical simulation on the dynamics in Taihu Lake, China (IV): Transportation and diffusion of conservative substance. J Lake Sci, 2002, 14(4) : 310-317. DOI: 10.18307/2002.0403. [胡维 平, 秦伯强. 太湖水动力学三维数值试验研究—4. 保守物质输移扩散: 湖泊科学, 2002, 14(4): 310-317].

[16] Prairie YT, Duarte CM, Kalff J. Unifying nutrient chlorophyll relationships in lakes. Can J Fish Aquat, 1989, 46( 7 ): 1176-1182.

[17] Mazumder A. Phosphorus-chlorophyll relationships under contrasting herbivory and thermal stratification: Predictions and patterns. Can J Fish Aquat Sci, 1994, 51(2) : 390-400.

[18] Nürnberg GK. Trophic state of clear and colored, soft- and hardwater lakes with special consideration of nutrients, anoxia, phytoplankton and fish. Lake Reservoir Manage, 1996, 12(4) : 432-447.

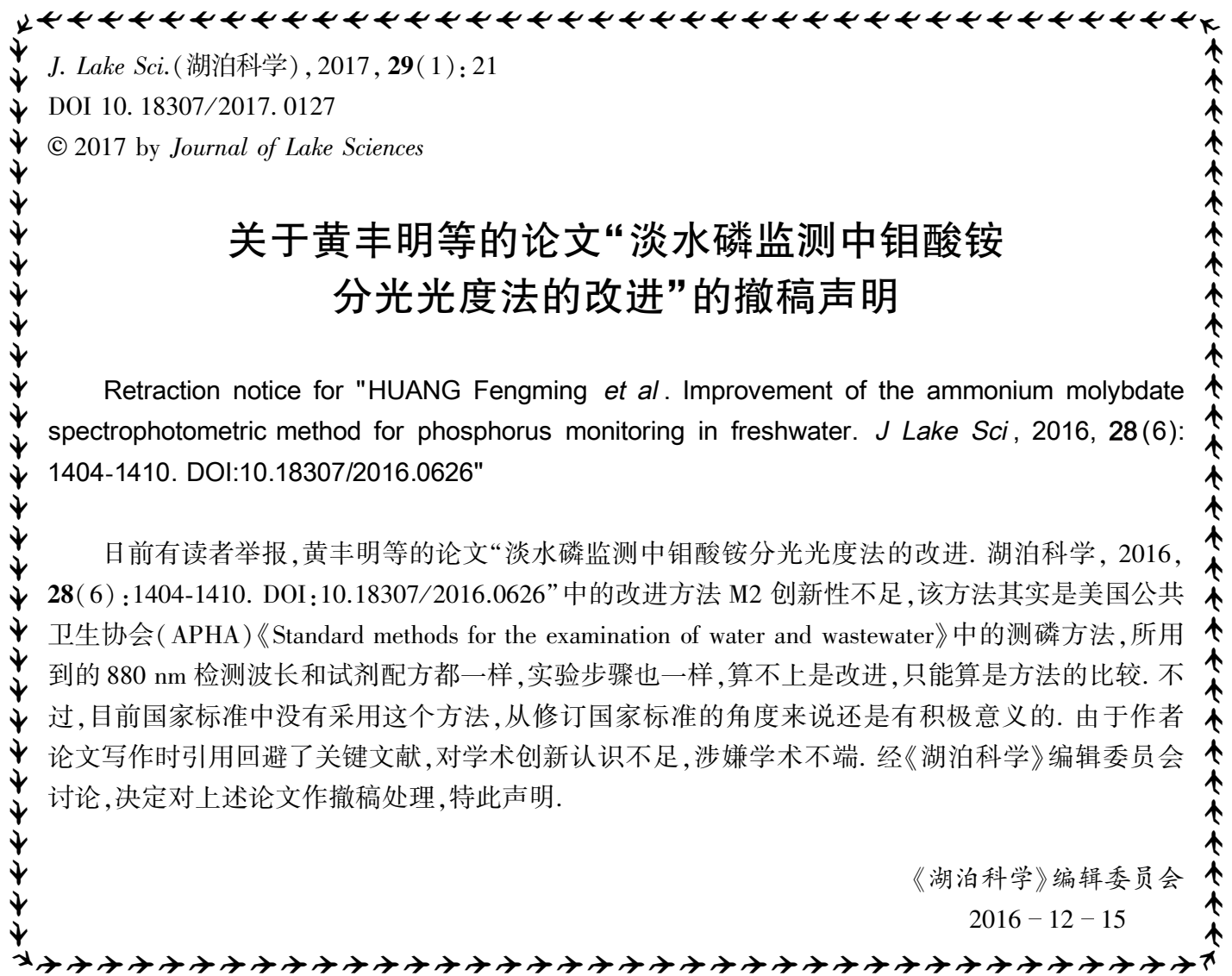

